DOI: 10.21105 /joss. 01918

\section{Software}

- Review ¿

- Repository u

- Archive ¿

Editor: Jed Brown ¿ד

Reviewers:

- @dhhagan

- Qsamjsilva91

Submitted: 05 November 2019

Published: 15 April 2020

\section{License}

Authors of papers retain copyright and release the work under a Creative Commons Attribution 4.0 International License (CC-BY).

\title{
PyCHAM: CHemistry with Aerosol Microphysics in Python
}

\author{
Simon O'Meara ${ }^{1,2}$, Shuxuan $\mathrm{X}_{\mathbf{u}^{1}}$, David Topping ${ }^{1}$, Gerard Capes ${ }^{3}$, \\ Douglas Lowe ${ }^{3}$, M. Rami Alfarra ${ }^{1,2}$, and Gordon McFiggans ${ }^{1,2}$
}

1 Department of Earth and Environmental Sciences, University of Manchester 2 National Centre for Atmospheric Science 3 Research Computing Services, University of Manchester

\section{Summary}

PyCHAM (CHemistry with Aerosol Microphysics in Python) is an open-access 0-D box model for aerosol chamber studies. Aerosol chambers provide a means for atmospheric scientists to interrogate aerosol processes (Finlayson-Pitts \& Pitts, 2000; Hidy, 2019; Schwantes et al., 2017). Allying PyCHAM with chamber measurements allows quantification of unknown parameters, such as branching ratios for oxidation schemes (Chen \& Griffin, 2005). Although several box models have already been published (Pierce et al., 2008; Roldin et al., 2019, 2014; Sunol, Charan, \& Seinfeld, 2018), PyCHAM is novel in its ease of accessibility and utility. To the best of our knowledge, PyBOX (Topping, Connolly, \& Reid, 2018), which formed the basis of PyCHAM, and AtChem (Borońska et al., 2019), are the only other open source box models with graphical user interfaces. However, PyCHAM provides a considerable upgrade to the functionality of both prior models, as AtChem only simulates gas-phase photochemistry and PyBOX has limited particle effects, whilst PyCHAM models significantly more particle microphysics (detailed below) and wall effects, in addition to gas-phase photochemistry. The intention therefore, is that it will be readily employed by research groups undertaking aerosol chamber measurements.

With air quality and climate models increasingly important to guiding sustainable societies, the accuracy of simulations must suffice (Tong et al., 2019). However, research shows that the simulated aerosol effects in these models provides a relatively high amount of uncertainty (Johnson et al., 2018). The combination of box models like PyCHAM with aerosol chamber measurements to better constrain aerosol processes is therefore necessary to ultimately improve societal sustainability.

At the time of writing, PyCHAM is being used to investigate the autoxidation of organic vapours in the atmosphere. The autoxidation process has recently been discovered to play a significant role in the formation of airbourne particulates (Ehn et al., 2014), however its exact chemical mechanism is yet to be elucidated. Through comparison of chamber measurements with PyCHAM outputs using various mechanism possibilities, a constrained autoxidation chemical scheme is being generated.

The model employs non-equilibrium equations to simulate the known processes occurring in aerosol chambers. At its core is integration of ordinary differential equations (ODEs) for gasphase photochemistry and gas partitioning to particles and walls. Here, the CVode function of the Assimulo package (Andersson, Führer, \& Åkesson, 2015) for ODE solvers is called on, using the backward differentiation formula of the Sundials solvers (Hindmarsh et al., 2005), which studies have shown is most reliable for solution of these equations (Jacobson, 2005). The general equation for chemical reactions is (Jacobson, 2005):

$$
\frac{d\left[i_{g}\right]}{d t}= \pm i_{s} k_{n}\left[a_{g}\right]^{a_{s}}\left[b_{g}\right]^{b_{s}}
$$


where square brackets represent concentrations, with $g$ representing the gas phase, $i$ is the affected component, $t$ is time, $k$ is the reaction rate coefficient for reaction $n, a$ and $b$ are example reactants, with stoichiometries $s$. The equation is positive for products of reactions and negative for reactants.

The gas-particle partitioning equation is (Jacobson, 2005):

$$
\frac{d\left[i_{g}\right]}{d t}=-k_{i}\left(\left[i_{g}\right]-p_{i}^{0} x_{i} K_{v}\right)
$$

where $k$ is the mass transfer coefficient, $p^{0}$ is the liquid saturation vapour pressure, $x$ is particle-phase mole fraction and $K_{v}$ is the Kelvin effect.

Gas partitioning to walls is an area of ongoing research (Zhang et al., 2015), therefore we provide an equation analogous to gas-particle partitioning given above:

$$
\frac{d\left[i_{g}\right]}{d t}=-k_{g w t} C_{w}\left(\left[i_{g}\right]-p_{i}^{0} \frac{\left[i_{w}\right]}{C_{w}}\right)
$$

where ${ }_{w}$ represents the wall, $k_{g w t}$ is the gas-wall mass transfer coefficient, $C_{w}$ is the effective absorbing concentration of the wall. Users set the values of $k_{g w t}$ and $C_{w}$ as wall effects vary significantly between chambers.

Outside the ODE solver, particle loss to walls, coagulation and nucleation are also solved, with equations for the former two given in Jacobson (2005) and the parameters inside the nucleation expression (for relevent experiments) tuned by the user. PyCHAM takes a sectional approach to particulates, dividing particles into a number of size bins and treating their changing size using the moving-centre approach (Jacobson, 2005). It builds upon PyBOX (Topping et al., 2018), which did not include coagulation, nucleation or a sectional method.

Several variables change between different aerosol chambers and different experiments; therefore, the software is designed to allow the user to set these with ease.

\section{Acknowledgements}

Funding has been provided by the EUROCHAMP-2020 research project (Oliveri, 2018). This project has received funding from the European Union's Horizon 2020 research and innovation programme under grant agreement No 730997 and the National Centre for Atmospheric Science.

\section{References}

Andersson, C., Führer, C., \& Åkesson, J. (2015). Assimulo: A unified framework for ODE solvers. Mathematics and Computers in Simulation, 116(0), 26-43. doi:10.1016/j.matcom.2015.04.007

Borońska, K., Jimack, P., Pilling, M., Rickard, A., Moreno, M., Waller, D., \& Young, J. (2019). AtChem on-line project. Retrieved from https://atchem.leeds.ac.uk/webapp/

Chen, J., \& Griffin, R. J. (2005). Modeling secondary organic aerosol formation from oxidation of $\alpha$-pinene, $\beta$-pinene and $d$-limonene. Atmospheric Environment, 39, 7731-7744. doi:10. 1016/j.atmosenv.2005.05.049 
Ehn, M., Thornton, J. A., Kleist, E., Sipilä, M., Junninen, H., Pullinen, I., Springer, M., et al. (2014). A large source of low-volatility secondary organic aerosol. Nature, 506, 476-479. doi:10.1038/nature13032

Finlayson-Pitts, B. J., \& Pitts, J. N. (2000). Chemistry of the upper and lower atmosphere: Theory, experiments and applications (1st ed.). San Diego: Academic Press.

Hidy, G. M. (2019). Atmospheric chemistry in a box or a bag. Atmosphere-Basel, 10(7). doi:10.3390/atmos10070401

Hindmarsh, A. C., Brown, P. N., Grant, K. E., Lee, S. L., Serban, R., Shumaker, D. E., \& Woodward, C. S. (2005). SUNDIALS: Suite of nonlinear and differential/algebraic equation solvers. ACM Transactions on Mathematical Software (TOMS), 31(3), 363-396.

Jacobson, M. Z. (2005). Fundamentals of atmospheric modeling (2nd ed.). Cambridge, U.K.: Cambridge University Press.

Johnson, J. S., Regayre, L. A., Yoshioka, M., Pringle, K. J., Lee, L. A., Sexton, D. M. H., Rostron, J. W., et al. (2018). The importance of comprehensive parameter sampling and multiple observations for robust constraint of aerosol radiative forcing. Atmospheric Chemistry and Physics, 18, 13031-13053. doi:10.5194/acp-18-13031-2018

Oliveri, M. (2018). EUROCHAMP 2020. Retrieved from https://www.eurochamp.org/ Eurochamp2020.aspx

Pierce, J., Englehart, G., Hildebrandt, L., Weitkamp, E., Parthak, E., \& Donahue, N. (2008). Constraining particle evolution from wall losses, coagulation and condensation-evaporation in smog chamber experiments: Optimal based size distribution measurements. Aerosol Science and Technology, 42. doi:10.1080/02786820802389251

Roldin, P., Ehn, M., Kurtén, T., Olenius, T., Rissanen, M. P., Sarnela, N., Elm, J., et al. (2019). The role of highly oxygenated organic molecules in the boreal aerosol-cloud-climate system. Nature Communications, 10. doi:10.1038/s41467-019-12338-8

Roldin, P., Ericsson, A. C., Nordin, E. Z., Hermansson, E., Mogensen, D., Rusanen, A., Boy, M., et al. (2014). Modelling non-equilibrium secondary organic aerosol formation and evaporation with the aerosol dynamics, gas- and particle-phase chemistry kinetic multilayer model adcham. Atmospheric Chemistry and Physics, 14. doi:10.5194/acp-14-7953-2014

Schwantes, R. H., McVay, R. C., Zhang, X., Coggon, M. M., Lignell, H., Flagan, R. C., Wennberg, P. O., et al. (2017). Advances in atmospheric chemistry, chapter 1: Science of the environmental chamber. World Scientific. doi:10.1142/10216

Sunol, A. M., Charan, S. M., \& Seinfeld, J. H. (2018). Computational simulation of the dynamics of secondary organic aerosol formation in an environmental chamber. Aerosol Science and Technology, 52, 470-482. doi:10.1080/02786826.2018.1427209

Tong, D., Geng, G., Jiang, K., Cheng, J., Zheng, Y., Hong, C., Yan, L., et al. (2019). Energy and emission pathways towards $\mathrm{pm}_{2.5}$ air quality attainment in the beijing-tianjin-hebei region by 2030. Science of the Total Environment, 692, 361-370. doi:10.1016/j.scitotenv. 2019.07.218

Topping, D., Connolly, P., \& Reid, J. (2018). PyBOX: An automated box-model generator for atmospheric chemistry and aerosol simulations. The Journal of Open Source Software, 3(28). doi:10.21105/joss.00755

Zhang, X., Schwantes, R. H., McVay, R. C., Lignell, H., Coggon, M. M., Flagan, R. C., \& Seinfeld, J. H. (2015). Vapor wall deposition in teflon chambers. Atmospheric Chemistry and Physics, 15, 4197-4214. doi:10.5194/acp-15-4197-2015 